\title{
Grid Security Infrastructure
}

National Cancer Institute

\section{Source}

National Cancer Institute. Grid Security Infrastructure. NCI Thesaurus. Code C80712.

A mechanism for secure transport that uses public key cryptography as the basis for its functionality. 